\title{
Corporações transnacionais e responsabilização na jurisdição estatal por violação a direitos humanos na cadeia produtiva*
}

\author{
Transnational corporations and the \\ accountability in the state's jurisdiction \\ by violations to human rights in the \\ productive chain
}

Carolina Spack Kemmelmeier ${ }^{1}$ Bruna Barbosa Pecin ${ }^{2}$
Recebido em: 27/09/2016. Aprovado em: 06/11/2016. Doutoranda pela Faculdade de Direito da Universidade de São Paulo. Mestre em Direito Negocial pela Universidade Estadual de Londrina. Graduada em Direito na Universidade Estadual de Maringá. Professora do Curso de Direito da Universidade Estadual do Oeste do Paraná, nas áreas de Direito do Trabalho e Direito Processual do Trabalho.

2 Graduanda em Direito pela Universidade Estadual do Oeste do Paraná, no campus de Foz do Iguaçu.

\section{Resumo}

O objetivo desse texto é refletir, no contexto do Direito Internacional Público, acerca da aplicabilidade do princípio da Jurisdição Universal para fins de responsabilização na jurisdição estatal de corporações transnacionais violadoras a direitos humanos na cadeia produtiva, notadamente os direitos dos trabalhadores. Para tanto, foi realizada uma revisão de literatura sobre o assunto, a partir da qual se discute a possibilidade de aplicação do Direito Internacional Público a pessoas privadas visando responsabilização de um ente integrante da cadeia produtiva em país diverso daquele em que o dano foi causado, analisando a efetividade do princípio da Jurisdição Universal para o resguardo dos direitos humanos nas relações de trabalho.

Palavras-chave: Direitos humanos. Corporações transnacionais. Cadeia produtiva. Jurisdição universal.

\footnotetext{
Abstract

The objective of this text is to reflect upon the context of International Public Law about the applicability of the Universal Jurisdiction principle towards the accountability in the state jurisdiction of transnational corporations that violate human rights in the productive chain, especially labor rights. Therefore, a literature review about the subject was realized, onwards it was discussed the possibility of applicability of the International Public Law on private persons, aiming the accountability of a member of a productive chain in a different country to which the damage was caused, analyzing the effectiveness of the Universal Jurisdiction principle to preserve human rights on labor relations.

Keywords: Human rights. Transnational corporations. Productive chain. Universal jurisdiction.
} 


\section{Introdução}

Observam-se substanciais alterações na estrutura de corporações transnacionais, que passaram a investir em novas maneiras de produção de bens e de prestação de serviços por meio da adoção da produção global com cadeias produtivas. Usualmente este fluxo se desenvolve entre países desenvolvidos e em desenvolvimento, se valendo aqueles das vantagens econômicas que estes provêm, o que pode estar associado a não efetivação dos direitos humanos de sua população.

Em decorrência das violações a direitos humanos em cadeias produtivas de corporações transnacionais e da complexidade da responsabilização destes violadores a nível internacional, alguns Estados têm adotado medidas para buscar a responsabilização interna destas corporações, mesmo quando a violação não ocorreu no território onde o julgamento será realizado, utilizando-se do princípio da Jurisdição Universal para este fim.

Diante desta prática, o presente artigo tem por objetivo analisar o impacto das cadeias globais de produção das corporações transnacionais nos direitos humanos, notadamente nos direitos dos trabalhadores, bem como da possibilidade de aplicação do Direito Internacional Público a pessoas privadas, entre elas corporações transnacionais, além do embasamento jurídico que justifica a responsabilização de uma corporação em país diverso daquele em que o dano foi causado.

\section{As corporações transnacionais e a cadeia de produção global}

A mundialização do capital, nova etapa de desenvolvimento do capitalismo, assim conceituada por Chesnais ${ }^{3}$, compreende uma mais intensa interação entre Estados e atores econômicos, possibilitando que as transações econômicas e a produção de bens e de serviços ultrapassassem os limites territoriais estatais de forma ampliada. Este movimento, associado à busca de grandes corporações por uma atuação mais competitiva no mercado desencadeou uma intensificação do processo de investimentos daquelas em países em desenvolvimento.

Observa-se uma maior interdependência econômica entre os países, que é fruto do fortalecimento e intensificação das transações transfronteiriças de bens e serviços, da massificação do pensamento único, da criação de um mercado mundial unificado, além do deslocamento de capital, que é impulsionado também pelo desenvolvimento e disseminação da tecnologia.

Este movimento se baseia na crença de que o crescimento e a prosperidade só são possíveis através da construção de uma economia global integrada. Esta tem como elementos centrais a liberação do comércio, a privatização e a macro estabilidade, sendo um movimento essencialmente transnacional, que funciona quando os Estados adotam referidos objetivos como normas comportamentais ${ }^{4}$.

Este cenário confere uma relevância significativa a determinados atores não estatais, denominados de corporações transnacionais, que são conceituadas, por Daillier, Pellet e Quoc Dinh, como "[a]quela[s] organizaç[ões] constituída[s] de um centro de decisão localizado em um país e por centros de atividade, dotados ou não de personalidade própria, situados em um ou em vários outros países" ${ }^{\prime \prime}$, sendo este o termo oficial adotado pela declaração da Organização das Nações Unidas (ONU) de $1974^{6}$.

Para Chesnais, as corporações transnacionais assumem a forma de empresas-rede, atestando a interconexão entre "as finanças concentradas e a grande indústria, estando elas na origem de "um importante processo de 'confusão' das fronteiras entre o "lucro" e a "renda" na formação do lucro de exploração dos grupos"

Esta forma de atuação das corporações transnacionais influencia diretamente nas relações de trabalho,

4 BACKER, Larry Catá. Multinational corporations, transnational law: the United Nations' norms on the responsibilities of transnational corporations as a harbinger of corporate social responsibility in international law. Columbia Human Rights Law Review, v. 37, 2005. Available at: <http://papers.ssrn.com/sol3/papers.cfm?abstract_ id=695641 > . Acessed: 30 Mar. 2016.

5 DALLIER, Patrick; PELLET, Alain; QUOC DINH, Nguyen. Direito internacional econômico e tributário. Brasília, v. 10, n. 1, p. 209-222, jan./jun. 2015. Disponível em: <http:// portalrevistas.ucb.br/index.php/RDIET/article/viewFile/5955/3918>. Acesso em: 20 jun. 2016.

6 CARVALHO, Marina Amaral Egydio de. Empresas transnacionais: a regulamentação do lobby no país receptor de investimentos e a promoção do desenvolvimento econômico. 2007. Dissertação (Mestrado) - Pontifícia Universidade Católica de São Paulo, São Paulo. 2007. Disponível em: <http://www.dominiopublico.gov.br/download/teste/ arqs/cp031716.pdf>. Acesso em: 27 mar. 2016.

7 CHESNAIS, François. A mundialização do capital. São Paulo: Xamã, 1996. 
resultando em uma maior instabilidade dos vínculos empregatícios e, consequentemente, na pressão para o rebaixamento dos salários e demais direitos trabalhistas, precarização na contratação do trabalho e das condições de segurança e saúde dos trabalhadores e no enfraquecimento da representação sindical ${ }^{8}$.

A mobilidade global do capital e a competição entre potenciais receptores de investimentos de uma corporação transnacional desencorajam iniciativas de reconhecimento e de efetivação dos direitos do trabalhador que possam aumentar o custo da força de trabalho ${ }^{9}$.

Desse modo, tornam-se cada vez mais recorrentes violações aos direitos humanos relacionadas às corporações transnacionais, que, segundo Peterke, "não cumprem [com] suas responsabilidades sociais ou até abusam delas, por motivos diferentes, ostentando seu poder em detrimento de determinados grupos e indivíduos" ${ }^{10}$.

Em razão da grande oferta de mão-de-obra frente à escassez de empregos e da busca pela minimização dos custos e maximização dos lucros há-se uma tendência à precarização do trabalho e ao emprego de formas degradantes de contratação, com salários em valores irrisórios, utilização de trabalho escravo e forçado, bem como o infantil e também de longas jornadas de trabalho.

Acerca da inserção do trabalho no campo da tutela dos direitos humanos, consoante Lucena Filho, "justifica-se, dentre outras razões de menor detalhamento, pelo relevo da figura do trabalho na vida humana e pela complexidade e tensões tão presentes na convivência entre os que detêm os meios de produção e os que efetivamente produzem"11. Nesta senda, há um crescente consenso in-

8 KEUNE, Marteen; SCHMIDT, Vera. Global capital strategies and trade union responses: towards transnational collective bargaining?" Internacional journal of labour research, v. 1, n. 2, p. 9-26, 2009. Available at: <http://www. ilo.org/actrav/info/pubs/WCMS_122375/lang--en/index. htm>. Acessed: 22 Jun. 2016.

9 STEINER, Henry J.; ALSTON, Philip; GOODMAN, Ryan. International human rights in context: law, politics, morals. 3. ed. Nova York: Oxford, 2007.

10 PETERKE, Sven. Manual prático de direitos humanos internacionais. Brasília: ESMPU, 2010. Disponível em: <https://escola.mpu.mp.br/linha-editorial/outras-publicacoes/Manual_Pratico_Direitos_Humanos_Internacioais. pdf $>$. Acesso em: 21 jun. 2016.

11 LUCENA FILHO, Humberto Lima de. Entre o universalismo e o relativismo teórico dos direitos humanos: a globalização e a (não) mercantilização do trabalho. In: CONPEDI/UFPB: direitos humanos e direito internacional e II - A humanização do direito e a horizontalização da justiça no século XXI. 2014, João Pessoa. Artigo... João Pessoa, 2014. p. 311-339, 2014. Disponível em: <http:// ternacional de que os direitos trabalhistas fundamentais estabelecidos no âmbito da Organização Internacional do Trabalho (OIT) também são direitos humanos fundamentais ${ }^{12}$.

Desde o início das suas atividades, a OIT reconhece a relação entre trabalho e dignidade humana, como se observa em sua declaração de 1919. Seguindo este raciocínio, a declaração da OIT sobre os Princípios e Direitos Fundamentais no Trabalho de 1998 consagrou como direitos humanos fundamentais trabalhistas a liberdade sindical e o reconhecimento efetivo do direito de negociação coletiva; a eliminação de todas as formas de trabalho forçado ou obrigatório; a abolição efetiva do trabalho infantil; e a eliminação da discriminação em matéria de emprego e ocupação, sendo sua efetivação compromisso de todos os membros pertencentes à Organização.

Reconhece-se, portanto, como dever estatal a intervenção para a real garantia e efetivação dos direitos inerentes à dignidade da pessoa humana no campo concernente ao Direito do Trabalho.

Entretanto, esta intervenção estatal usualmente encontra obstáculos, considerando que os Estados costumeiramente se mostram incapazes de adotar medidas de responsabilização das corporações transnacionais por suas ações danosas aos direitos dos trabalhadores que empregam em cadeias globais. Isto ocorre por inúmeras razões, que vão de motivações políticas a incapacidade técnica.

Especificamente quanto às cadeias globais de produção, entendem-se estas como denominação que representa o atual estágio de dispersão geográfica e a fragmentação em diversas etapas da produção. Ou seja, consoante o IV relatório do Bureau Internacional do Trabalho de Genebra sobre Trabalho Decente nas cadeias globais de produção, estas podem ser conceituadas como a organização transfronteiriça das atividades necessárias para produzir bens e serviços e fornece-los a consumidores através de "inputs" e diversas fases de desenvolvimento, produção e entrega ${ }^{13}$.

publicadireito.com.br/artigos/?cod=d926f01bf79efe $88>$. Acesso em: 21 jun. 2016.

12 MATTIOLI, Maria Cristina. As políticas públicas para promover e implementar os direitos fundamentais no trabalho e a integração econômica internacional. Planejamento e políticas públicas, n. 26, p. 135-154, 2003. Disponível em: <http://www.ipea.gov.br/ppp/index.php/PPP/ article/view/57>. Acesso em: 21 jun. 2016.

13 INTERNATIONAL LABOUR OFFICE. Decent work in supply chains, report IV, 2016. Available at: <http://www. 
Através da produção em cadeias globais, as corporações transnacionais buscam minimizar os custos do produto, se valendo de redes de externalização da produção (sub-contratados). Maeoka, ao analisar a instalação de corporações transnacionais em determinadas regiões, consigna que estas partem em "busca da mão-de-obra nos lugares onde a remuneração é baixa e a estrutura de proteção dos trabalhadores é visivelmente precária"14.

Ainda, o relatório do Bureau Internacional do Trabalho reconhece que as "pressões globais nos preços dos produtores, os prazos de entrega e a intensa competição entre fornecedores podem influenciar negativamente nos valores de salários, condições de trabalho e no respeito pelos direitos fundamentais dos trabalhadores destas cadeias de produção" ${ }^{15}$, tudo em busca da diminuição do preço da produção, buscando assim se tornar mais competitivos e atrativos para investimentos.

Diante deste contexto, em razão da distribuição pelas empresas transnacionais da produção na forma de cadeias produtivas compostas por filiais, subcontratadas e fornecedoras localizadas em territórios distintos, o sistema jurídico interno do país da matriz dificilmente levará em consideração a ofensa a direitos humanos cometida por estas nos países das subcontratadas, mesmo quando a matriz agiu em cumplicidade com a filial.

Consoante entendimento de Santinho, "a presença cada vez maior destas pessoas privadas em países mais dependentes causam, de forma direta ou indireta, o aumento dos conflitos, muitas vezes violando o padrão ético permitido pelo Direito Internacional Público"16.

A partir deste panorama, analisam-se os funda-

ilo.org/ilc/ILCSessions/105/reports/reports-to-the-conference/WCMS_468097/lang--en/index.htm>. Acessed: 12 Aug. 2016.

14 MAEOKA, Erika. Os desafios do direito do trabalho no contexto da expansão do comércio internacional. Revista do Tribunal Regional do Trabalho da $9^{a}$ Região, Curitiba, v. 32, p. 07, 2009.

International Labour Office. Decent work in supply chains, report IV, 2016. Disponível em: <http://www.ilo.org/ ilc/ILCSessions/105/reports/reports-to-the-conference/ WCMS_468097/lang--en/index.htm>. Acesso em: 12 Aug. 2016.

16 SANTINHO, Guilherme Sampieri. Responsabilidade internacional das corporações por ofensa aos direitos humanos: Estado e responsabilidade: questões críticas. 2013. Dissertação (Mestrado) - Universidade Estadual do Norte do Paraná, UENP, Jacarezinho. 2013. Disponível em: <http://www.uenp.edu.br/index.php/estagiarios/doc_ view/4056-guilherme-sampieri-santinho $>$. Acesso em: 27 mar. 2016 mentos jurídicos de responsabilização destas corporações transnacionais por violações a direitos humanos em sua cadeia produtiva, notadamente a denominada responsabilização doméstica, conforme se demonstrará a seguir.

\section{Justificativa e possibilidades de responsabili- zação de corporações transnacionais}

Conforme o referencial prevalecente no Direito Internacional Público ${ }^{17}$, as pessoas jurídicas não são tidas como sujeitos de Direito Internacional Público, o que possibilitaria a aplicação a elas das normas internacionais de direitos humanos por organizações internacionais, o que resulta em uma lacuna nos mecanismos de proteção internacional aos direitos humanos.

Tradicionalmente, o Direito Internacional Público seria destinado apenas à tutela dos Estados e de suas relações jurídicas. Contudo, este panorama sofreu alterações após a Segunda Guerra Mundial com a criação de organizações internacionais de grande relevância, como a ONU, em 1945, figurando estas como atores fundamentais na reestruturação das relações internacionais no momento pós-guerra ${ }^{18}$.

O destaque destas organizações a nível internacional impôs que fossem reconhecidas como sujeitos do Direito Internacional. Além disso, sua atuação em âmbito global e a complexidade das relações jurídicas travadas por estas organizações foram motivos determinantes para sua inclusão neste rol. Consequentemente, houve a abertura de espaço para que outros entes fossem considerados como sujeitos do direito internacional.

Devido ao crescimento das normas internacionais sobre Direitos Humanos, as pessoas privadas integram cada vez mais o Direito Internacional Público, com a progressiva atribuição de direitos e deveres a estes novos atores. Deste modo, normas internacionais de proteção aos Direitos Humanos, como, por exemplo, não cometer crimes de guerra, genocídio, apartheid e pirataria passam a ser direcionadas também as pessoas privadas.

Observa-se, deste modo, que o Direito Internacional Público não somente impõe deveres aos Estados, mas também a outros atores, como as pessoas privadas. Percebe-se, assim, que não há limites definitivos que impe-

17 REZEK, Francisco. Direito internacional público. São Paulo: Saraiva, 2010

18 AMARAL JUNIOR, Alberto do. Curso de direito internacional público. São Paulo: Saraiva, 2014. 
çam a inclusão de novos atores no Direito Internacional Público.

Desta forma, mesmo não sendo possível caracterizar as corporações transnacionais como sujeitos do Direito Internacional Público em sentido pleno, conforme Santinho ${ }^{19}$ e a partir da leitura de Mazzuoli $^{20}$ e Cretella Neto $^{21}$, conclui-se que estas podem ser reconhecidas ao menos como atores do Direito Internacional Público, a elas se atribuindo direitos e deveres, para que não apenas defendam seus interesses a nível internacional, mas também sejam responsabilizadas de tal maneira em caso de violação às normas de Direito Internacional Público.

Não obstante este entendimento, o que se observa através da análise histórica das tentativas de responsabilização internacional de corporações transnacionais por violação a direitos humanos é que inexistem mecanismos internacionais neste sentido ${ }^{22}$.

Contudo, considerando-se a primordialidade de responsabilização de transnacionais que violam direitos humanos em sua cadeia de produção, bem como a necessidade de reparação daqueles que foram lesados, e tendo em vista a ausência de mecanismos internacionais nesse sentido alguns países vêm se utilizando da construção doutrinária e jurisprudencial a respeito da Jurisdição Universal para responsabilizar corporações internamente por violações praticadas em jurisdições distintas, sendo este o objeto de aprofundamento no próximo capítulo ${ }^{23}$.

19 SANTINHO, Guilherme Sampieri. Responsabilidade internacional das corporações por ofensa aos direitos humanos: Estado e responsabilidade: questões críticas. 2013. Dissertação (Mestrado) - Universidade Estadual do Norte do Paraná, UENP, Jacarezinho. 2013. Disponível em: <http://www.uenp.edu.br/index.php/estagiarios/doc view/4056-guilherme-sampieri-santinho>. Acesso em: 27 mar. 2016.

20 MAZZUOLI, Valério de Oliveira. Curso de direito internacional público. 7. ed. São Paulo: Revista dos Tribunais, 2013.

21 CRETELLA NETO, José. Empresa transnacional e direito internacional: exame do tema à luz da globalização. Rio de Janeiro: Forense, 2006.

22 SALAZAR, Claudia T. Applying international human rights norms in the United States: holding multinational corporations accountable in the United States for international human rights violations under the alien tort claims act. Journal of Civil Rights and Economic Development, v. 19, n. 1, 2004. Available at: <http://scholarship.law.stjohns.edu/jcred/vol19/iss1/10>. Acessed: 22 Jun. 2016.

23 HOSHINO, Thiago de Azevedo Pinheiro; PRIOSTE, Fernando Gallardo Vieira. Transnacionais no banco dos réus: experiências e possibilidades de responsabilização. Curitiba: Terra de Direitos, 2009.

\section{A jurisdição universal}

Em razão da não responsabilização no Estado em que se deu a violação de direitos humanos, muitas vezes pela desídia dos próprios entes estatais, bem como diante da inexistência de mecanismos a nível internacional, Estados assumem esta responsabilidade se valendo do princípio da Jurisdição Universal.

Como explica Joyner, o princípio da Jurisdição Universal surgiu inicialmente no contexto de prossecuções penais e subsequentemente se expandiu para áreas da litigância civil. $O$ rol de violações que comportam a aplicação do princípio da Jurisdição Universal foi alargado após os crimes contra a humanidade cometidos na Segunda Guerra Mundial. Em virtude da seriedade destes crimes e pelo fato de serem tão graves e de preocupação universal, eles afetam não apenas a segurança e os interesses da comunidade internacional, como também a moral, devendo seus perpetradores ser responsabilizados ${ }^{24}$.

Para Reis e Lessa, "a base conceitual da [J]urisdição [U]niversal é que tais infrações geram efeitos à comunidade internacional como um todo, ofendendo a própria consciência de humanidade" ${ }^{25}$. Assim, extrai-se que ao se utilizar da Jurisdição Universal, Estados podem responsabilizar internamente, por meio de sua jurisdição, aqueles que cometeram determinadas infrações, ainda quando estas não apresentem nexo, em sua acepção tradicional, com o Estado.

As autoras acima mencionadas atribuem essa possibilidade ao fato de que as transgressões aos direitos humanos são questões de política pública internacional, passando todos os Estados a serem competentes para julgamento quando estes direitos são ofendidos, uma vez que seus efeitos são suportados por todos os territórios nacionais.

JOYNER, Christopher C. Arresting impunity: the case for universal jurisdiction in bringing war criminals to accountability. Law and Contemporary Problem, v. 59, p. 153-172, 1996. Available at: <http://scholarship.law.duke. edu/lcp/vol59/iss4/12>. Acessed: 18 Aug. 2016.

25 REIS, Daniela Murados; LESSA, Rafaela Ribeiro Zauli. Submissão das corporações a sanções internacionais e meios não-estatais de reparação: possíveis soluções à ineficácia do direito ao trabalho decente. Anuário Brasileiro de Direito Internacional, Belo Horizonte, 2014. Disponível em: <http://www.cedin.com.br/wp-content/ uploads/2014/05/Submiss\%C3\%A3o-das-Corpora\%C3\%A7\%C3\%B5es-\%C3\%A0-San\%C3\%A7\%C3\%B5es-Internacionais-e-Meios-N\%C3\%A3o-Estatais-de-Repara\%C3\%A7\%C3\%A3o.pdf>. Acesso em: 05 abr. 2016. 
Por meio da Jurisdição Universal, a responsabilização ocorre independentemente do nexo que o Estado tem com a ofensa, com o ofensor, ou até mesmo com a vítima, mesmo se os nacionais daquele país não tenham sido gravemente afetados pelo ato.

Acerca da aplicação do princípio da Jurisdição Universal às violações a direitos humanos cometidas na produção de bens e serviços em cadeia produtiva global, tem-se que esta prática pode ser utilizada a fim de coibir as ações de corporações transnacionais que, ao se utilizar da distribuição internacional da produção a fim de diminuir os custos produtivos, se valem da contratação de fornecedores que não são submetidos à efetiva fiscalização no que tange às condições de emprego em seu Estado de origem, especialmente para responsabilização dos produtores finais, os maiores favorecidos pela precarização laboral.

Desta forma, ante a inexistência ou precariedade de fiscalização, bem como de normas e mecanismos de proteção aos direitos dos trabalhadores, violações a direitos humanos, notadamente nas relações de trabalho, como emprego de jornadas excessivas de trabalho, mão-de-obra não assalariada e infantil se tornam recorrentes no âmbito da produção descentralizada.

A estas violações a direitos ocasionadas na cadeia de produção é primordial a aplicação do princípio da Jurisdição Universal para julgamento extraterritorial dos perpetradores, tendo em vista a gravidade das transgressões e as dificuldades na efetiva responsabilização no local onde ocorrem, como já abordado.

Assim, não obstante as dificuldades acima apontadas e a lacuna existente no Direito Internacional Público quanto a responsabilização de pessoas privadas por violações a direitos humanos através de mecanismos internacionais vem-se, conforme demonstrado, ampliando a prática de adoção de ferramentas internas com o intuito de suprir essa falha.

Piovesan elucida que a proteção aos direitos humanos, tendo em vista sua relevância e interesse internacional, não deve ser reservada apenas ao domínio de determinado Estado, ou se restringir apenas a sua competência, sendo esta ideia fortalecida pelo princípio da Jurisdição Universal ${ }^{26}$. A partir da análise do contexto atual do Direito Internacional dos Direitos Humanos obser-

26 PIOVESAN, Flávia. Direitos humanos e justiça internacional. São Paulo: Saraiva, 2007. va-se um maior reconhecimento por parte dos Estados do princípio da Jurisdição Universal, sendo expresso em legislações nacionais, como por exemplo, a dos Estados Unidos da América (EUA) ${ }^{27}$.

No caso específico dos EUA, a busca por alternativas desvinculadas de organismos internacionais para efetuar a responsabilização de corporações transnacionais quando da violação de direitos humanos tem se concretizado por meio do Alien Torts Claim Act (ATCA).

O ATCA prevê jurisdição original da corte federal sobre qualquer ação civil interposta por um estrangeiro a respeito de danos cometidos em decorrência de violações à lei das nações ou a tratados internacionais vigentes nos EUA. Há, portanto, reconhecimento da jurisdição interna para julgar e responsabilizar agentes que cometam atos ilícitos internacionais, independente do país em que ocorreram, com o fundamento de que o Direito Internacional Público é fonte do direito estadunidense.

Consoante Salazar ${ }^{28}$, a aplicação da norma teve início com o caso Filartiga v. Irala-Pena, que atribuiu jurisdição a cortes federais para julgamento de casos que violassem a lei das nações. Desde então, as cortes federais americanas expandiram a jurisdição do ATCA para abranger variadas categorias de violações a normas federais, incluindo ainda em sua jurisdição a aplicação àqueles atos perpetrados não apenas por Estados, mas também por agentes estatais, indivíduos e também corporações transnacionais.

O caso Kadic $v$ Karadzic é outra amostra relevante da utilização da ATCA, trazendo a possibilidade da aplicação da norma a entes de direito privado, que em seu julgamento entendeu ser possível à aplicação do estatuto a pessoas privadas, inclusive corporações transnacionais, independentemente de sua vinculação a algum Estado, concluindo ainda' que estas devem cumprir as normas de

27 SALAZAR, Claudia T. Applying international human rights norms in the United States: holding multinational corporations accountable in the united states for international human rights violations under the alien tort claims act. Journal of Civil Rights and Economic Development, v. 19, n. 1, 2004. Available at: <http://scholarship.law.stjohns.edu/jcred/vol19/iss1/10>. Acessed: 22 Jun. 2016.

28 SALAZAR, Claudia T. Applying international human rights norms in the United States: holding multinational corporations accountable in the united states for international human rights violations under the alien tort claims act. Journal of Civil Rights and Economic Development, v. 19, n. 1, 2004. Available at: <http://scholarship.law.stjohns.edu/jcred/vol19/iss1/10>. Acessed: 22 Jun. 2016. 
Direito Internacional Público, consoante explanação de Santinho ${ }^{29}$.

Segundo Salazar ${ }^{30}$, a evolução da aplicação da ATCA a casos envolvendo corporações transnacionais é condizente com a expansão da estrutura do sistema internacional e com a evolução do direito internacional, tendo em vista a presença consistente das corporações transnacionais no nosso atual sistema internacional. Também se justifica a aplicação do ATCA em desfavor de corporações transnacionais pelo status global por elas adquirido, sendo este equiparado ao de sujeitos do direito internacional público, conforme tratado nos capítulos acima.

A aplicação do ATCA fundamenta uma série de ações propostas nesse país, inclusive de litígios atuais envolvendo três das maiores companhias de produção de chocolate do país por violações a direitos humanos em sua cadeia produtiva, mais especificamente pela rede de fornecedores de cacau do oeste da África, que se utilizam do trabalho escravo infantil na produção ${ }^{31}$. As ações propostas têm por objeto a condenação ao pagamento de indenização e a proibição contra práticas comerciais injustas e enganosas ${ }^{32}$.

Neste contexto, o princípio da jurisdição universal, exemplificado por meio do ATCA se coloca como mecanismo para a responsabilização no âmbito da jurisdição estatal em localidade diversa da violação dos direitos humanos no âmbito das cadeias globais de produção, contribuindo para a busca da efetivação da proteção dos direitos dos trabalhadores.

29 SANTINHO, Guilherme Sampieri. Responsabilidade internacional das corporações por ofensa aos direitos humanos: Estado e responsabilidade: questões críticas. 2013. Dissertação (Mestrado) - Universidade Estadual do Norte do Paraná, UENP, Jacarezinho. 2013. Disponível em: <http://www.uenp.edu.br/index.php/estagiarios/doc view/4056-guilherme-sampieri-santinho $>$. Acesso em: 27 mar. 2016.

30 SALAZAR, Claudia T. Applying International Human Rights Norms in the United States: Holding Multinational Corporations Accountable in the United States For International Human Rights Violations Under the Alien Tort Claims Act. Journal of Civil Rights and Economic Development, v. 19, n. 1, 2004. Avaiable at: <http://scholarship.law. stjohns.edu/jcred/vol19/iss1/10>. Acessed: 22 Jun. 2016.

31 IOVINO, Nicholas. Chocolate Giants Face Slave Labor Lawsuits, 2015. Avaiable at: <http://www.courthousenews. com/2015/09/29/chocolate-giants-face-slave-labor-lawsuits.htm>. Acessed: 22 Jun. 2016

32 IOVINO, Nicholas. Chocolate Giants Face Slave Labor Lawsuits, 2015. Avaiable at: <http://www.courthousenews. com/2015/09/29/chocolate-giants-face-slave-labor-lawsuits.htm>. Acessed: 22 Jun. 2016

\section{Conclusão}

A mundialização do capital amplia a relevância das corporações transnacionais, que, ao investirem na produção através da utilização de cadeias produtivas globais, buscam maximizar os lucros e minimizar os custos, se tornando ainda mais competitivas no mercado.

Nesta senda, tem sido constatada uma tendência à violação dos direitos humanos nas relações de trabalho das cadeias produtivas globais, tais como trabalho escravo e trabalho infantil. Isto ocorre porque a prática da contratação pelas corporações transnacionais com países em desenvolvimento estimula a violação a direitos humanos no sentido de que estes, tendo em vista a necessidade de investimentos estrangeiros, ignoram normas do direito internacional público ao violar direitos humanos na produção de bens e serviços pela precariedade das condições de trabalho oferecidas aos trabalhadores, tudo em busca da diminuição do preço da produção.

Apesar das corporações transnacionais não serem reconhecidas como sujeitos do Direito Internacional Público, a elas são atribuídos direitos e deveres no campo dos direitos humanos. Entretanto, não obstante este entendimento, o que se observa através da análise histórica das tentativas de responsabilização internacional de corporações transnacionais por violação a direitos humanos é que inexistem mecanismos internacionais neste sentido.

Contudo, tendo em vista a primordialidade da responsabilização destas corporações quando da violação a direitos humanos na cadeia de produção, buscam-se mecanismos domésticos que tragam esta possibilidade, sendo o princípio da Jurisdição Universal adotado para este fim, uma vez que ele viabiliza o julgamento interno daqueles que cometeram graves infrações a direitos humanos, ainda que estas não apresentem nexo com o Estado julgador.

Os crimes abarcados pelo princípio são aqueles que apresentam gravidade tal qual a responsabilização dos cometedores deve ser objetivada independentemente do nexo que o Estado responsabilizador tem com a ofensa, com o ofensor, ou até mesmo com a vítima, mesmo se os nacionais daquele país não tenham sido gravemente afetados pelo ato. Isto se justifica porque tais ações ofendem a comunidade internacional como um todo.

Exemplo da utilização do princípio da Jurisdição Universal para responsabilização doméstica pode ser observado através da aplicação do Alien Torts Claim Act (ATCA) nos Estados Unidos da América (EUA). Este tem 
fundamentado a responsabilização de empresas privadas que cometam atos ilícitos internacionais, inclusive em matéria de direitos humanos nas cadeias produtivas, independentemente do local onde efetivamente ocorreram, já tendo servido para embasar dezenas de ações nos EUA neste sentido, se mostrando como uma solução adequada para a proteção e efetivação dos direitos humanos.

\section{Referências}

AMARAL JUNIOR, Alberto do. Curso de direito internacional público. São Paulo: Saraiva, 2014.

BACKER, Larry Catá. Multinational corporations, transnational law: the United Nations' norms on the responsibilities of transnational corporations as a harbinger of corporate social responsibility in international law. Columbia Human Rights Law Review, v. 37, 2005. Avaiable at: <http://papers.ssrn.com/sol3/papers.cfm?abstract_ id=695641 $>$. Acessed: 30 Mar. 2016.

CARVALHO, Marina Amaral Egydio de. Empresas transnacionais: a regulamentação do lobby no país receptor de investimentos e a promoção do desenvolvimento econômico. 2007. Dissertação (Mestrado) - Pontifícia Universidade Católica de São Paulo São Paulo. 2007. Disponível em: <http://www.dominiopublico.gov.br/download/teste/arqs/cp031716.pdf >. Acesso em: 27 mar. 2016.

CHESNAIS, François. A mundialização do capital. São Paulo: Xamã, 1996.

CRETELLA NETO, José. Empresa transnacional e direito internacional: exame do tema à luz da globalização. Rio de Janeiro: Forense, 2006.

DALLIER, Patrick; PELLET, Alain; QUOC DINH, Nguyen. Direito internacional econômico e tributário. Brasília, v. 10, n. 1, p. 209-222, jan./jun. 2015. Disponível em: $<$ http://portalrevistas.ucb.br/index.php/RDIET/article/ viewFile/5955/3918>. Acesso em: 20 jun. 2016.

HOSHINO, Thiago de Azevedo Pinheiro; PRIOSTE, Fernando Gallardo Vieira. Transnacionais no banco dos réus: experiências e possibilidades de responsabilização. Curitiba: Terra de Direitos, 2009.

IOVINO, Nicholas. Chocolate Giants Face Slave Labor Lawsuits, 2015. Avaiable at: <http://www.courthousenews.com/2015/09/29/chocolate-giants-face-slave-labor-lawsuits.htm>. Acessed: 22 Jun. 2016

JOYNER, Christopher C. Arresting impunity: the case for universal jurisdiction in bringing war criminals to accountability. Law and Contemporary Problem, v. 59, p. 153-172, 1996. Available at: <http://scholarship.law.duke. edu/lcp/vol59/iss4/12>. Acessed: 18 Aug. 2016.
KEUNE, Marteen; SCHMIDT, Vera. Global capital strategies and trade union responses: towards transnational collective bargaining? Internacional journal of labour research, v. 1, n. 2, p. 9-26, 2009. Available at: <http://www. ilo.org/actrav/info/pubs/WCMS_122375/lang--en/index.htm>. Acessed: 22 Jun. 2016.

LUCENA FILHO, Humberto Lima de. Entre o universalismo e o relativismo teórico dos Direitos Humanos: a globalização e a (não) mercantilização do trabalho. In: CONPEDI/UFPB: Direito Internacional e Direitos $\mathrm{Hu}$ manos II - A humanização do Direito e a Horizontalização da Justiça no Século XXI. 2014, João Pessoa. Artigo... João Pessoa, 2014. p. 311-339, 2014. Disponível em: $<$ http://publicadireito.com.br/artigos/?cod=d926f01bf79efe88>. Acesso em: 21 jun. 2016.

MAEOKA, Erika. Os desafios do direito do trabalho no contexto da expansão do comércio internacional. Revista do Tribunal Regional do Trabalho da $9^{a}$ Região, Curitiba, v. 32, p. 07, 2009.

MATTIOLI, Maria Cristina. As políticas públicas para promover e implementar os direitos fundamentais no trabalho e a integração econômica internacional. Planejamento e Políticas Públicas, n. 26, p. 135-154, 2003. Disponível em: < http://www.ipea.gov.br/ppp/index.php/PPP/ article/view/57>. Acesso em: 21 jun. 2016.

MAZZUOLI, Valério de Oliveira. Curso de direito internacional público. 7. ed. São Paulo: Revista dos Tribunais, 2013.

PETERKE, Sven. Manual prático de direitos humanos internacionais. Brasília: ESMPU, 2010. Disponível em: $<$ https://escola.mpu.mp.br/linha-editorial/outras-publicacoes/Manual_Pratico_Direitos_Humanos_Internacioais. pdf $>$. Acesso em: 21 jun. 2016.

PIOVESAN, Flávia. Direitos humanos e justiça internacional. São Paulo: Saraiva, 2007.

REIS, Daniela Murados; LESSA, Rafaela Ribeiro Zauli. Submissão das corporações a sanções internacionais e meios não-estatais de reparação: possíveis soluções à ineficácia do direito ao trabalho decente. Anuário Brasileiro de Direito Internacional, Belo Horizonte, 2014. Disponível em: <http://www.cedin.com.br/wp-content/ uploads/2014/05/Submiss\%C3\%A3o-das-Corpora\%C3\%A7\%C3\%B5es-\%C3\%A0-San\%C3\%A7\%C3\%B5es-Internacionais-e-Meios-N\%C3\%A3o-Estatais-de-Repara\%C3\%A7\%C3\%A3o.pdf>. Acesso em: 05 abr. 2016.

REZEK, Francisco. Direito internacional público. São Paulo: Saraiva, 2010.

SALAZAR, Claudia T. Applying international human rights norms in the United States: Holding multinational corporations accountable in the united states for interna- 
tional human rights violations under the alien tort claims act. Journal of Civil Rights and Economic Development, v. 19, n. 1, 2004. Available at: <http://scholarship.law. stjohns.edu/jcred/vol19/iss1/10>. Acessed: 22 Jun. 2016.

SANTINHO, Guilherme Sampieri. Responsabilidade internacional das corporações por ofensa aos direitos humanos. Estado e Responsabilidade: questões críticas. 2013. Dissertação (Mestrado) - Universidade Estadual do Norte do Paraná, UENP, Jacarezinho. 2013. Disponível em: <http://www.uenp.edu.br/index.php/estagiarios/doc_ view/4056-guilherme-sampieri-santinho $>$. Acesso em: 27 mar. 2016.

STEINER, Henry J.; ALSTON, Philip; GOODMAN, Ryan. International human rights in context: law, politics, morals. 3. ed. Nova York: Oxford, 2007. 